\title{
Rapid Determination of Vitamin D-2, D-3, and Their 25 Hydroxy Metabolites in Human Plasma by Ultra Performance Liquid Chromatography
}

\author{
Syed N. Alvi, Rajaa F. Hussein, Ahmed Yusuf and Muhammad M. Hammami \\ Clinical Studies and Empirical Ethics Department, King Faisal Specialist Hospital \& Research Center, Riyadh 11211, Kingdom of \\ Saudi Arabia
}

\begin{abstract}
A simple and rapid ultra performance liquid chromatography (UPLC) method for simultaneous determination of vitamin D-2 (VD-2), vitamin D-3 (VD-3), 25-hydroxyvitamin D-2 (25(OH)VD-2), and 25-hydroxyvitamin D-3 (25(OH)VD-3) in human plasma was developed and validated. Plasma samples were deproteinized with acetonitrile and then extracted with hexane. After evaporation, the residue was dissolved in the mobile phase, centrifuged, and the clear solution was injected into the system. Using dodecanophenone as an internal standard (IS), analytes separation was achieved by UPLC BEH C-18 column and a mobile phase that consisted of methanol, acetonitrile, and water ( $\mathrm{pH}$ 3.0) and used in a gradient elution mode with a total run time of 14 minutes. The eluents were monitored by photodiode array detector (wavelength $265 \mathrm{~nm}$ ). The relationship between plasma concentration of each of the four analytes and its peak area ratio (analyte to IS) was linear over the range of 2.5-100 ng/ml. Inter-day coefficient of variation and bias were $\leq 13.4 \%$ and $\leq 18 \%$, respectively, for all the four analytes. Mean extraction recovery ranged from $77 \%-93 \%$ for the four analytes and was $85 \%$ for the IS.
\end{abstract}

Key words: 25-Hydroxyvitamin D-2, 25-Hydroxyvitamin D-3, Vitamin D-2, Vitamin D-3, Dodecanophenone, UPLC.

\section{Introduction}

Vitamin D is an essential micronutrient that plays an important role in protecting from bone and potentially other metabolic diseases in humans [1, 2]. Vitamin D exists in two forms: vitamin D-3 (cholecalciferol) synthesized from 7-dehydrochlesterol in the skin by the action of UVB radiation and vitamin D-2 (ergocalciferol) derived from plant/yeast by irradiation of ergosterol. Vitamin D made in the skin or supplied in the diet is metabolized in the liver to 25-hyroxyvitamin $\mathrm{D}$, which is the major circulating form of vitamin $\mathrm{D}$ and best indicator of vitamin D status. 25-hydroxyvitamin $\mathrm{D}$ is further metabolized in the kidney to 1,25 dihydroxyvitamin $\mathrm{D}$, the active metabolite $[3,4]$.

Deficiency of vitamin D is common due to inadequate sun exposure. Recent studies reported that

Corresponding author: Muhammad M. Hammami, M.D., $\mathrm{Ph} . \mathrm{D}$., professor, research field: endocrinology study design.
$30 \%-50 \%$ of children and adults in many countries had 25 hydroxyvitamin D levels below $20 \mathrm{ng} / \mathrm{ml} \mathrm{[5].}$

25-Hydroxyvitamin D-3 (25(OH)VD-3) and 25-hydroxyvitamin D-2 (25(OH)VD-2) levels in human plasma have been determined by radioimmunoassay and most commonly by high performance liquid chromatography (HPLC) or liquid chromatography/tandem-mass spectrometry (LCMS) [6-16]. HPLC method for simultaneous determination of 25(OH)VD-3, 25(OH)VD-2, and VD-3 in plasma has been reported by Aksnes [15]. However, because of an interfering peak, the method was not suitable for measurement of VD-2 level. We previously reported an HPLC method [16] for simultaneous measurement of vitamin D-2 (VD-2), vitamin D-3 (VD-3), 25(OH)VD-2, and 25(OH)VD-3. However, the method required relatively large sample volume and long run time.

The objective of the current study was to develop, 
validate, and apply a simple UPLC assay for simultaneous quantification of VD-2, VD-3, 25(OH)VD-2, and 25(OH)VD-3 in human plasma using small sample volume and short run time.

\section{Materials and Methods}

\subsection{Apparatus}

Chromatography was performed on Waters Acquity UPLC system (Waters Associates Inc, Milford, MA, USA) consisting of quaternary pump, autosampler, column thermostat, and photodiode array detector set at $265 \mathrm{~nm}$. A reversed-phase UPLC BEH C-18 (2.1 × 100 $\mathrm{mm}, 1.7 \mu \mathrm{m})$ column protected by a guard pak pre-column BEH C-18, $1.7 \mu \mathrm{m}$ insert was used for separation. The data were collected with a Pentium IV computer using Empower Chromatography Manager Software.

\subsection{Chemicals and Reagents}

All chemicals were of analytical grade unless stated otherwise. Vitamin D-2 and vitamin D-3 were purchased from Acros Organics, New Jersey, USA, whereas 25(OH)VD-2 and 25(OH)VD-3 and dodecanophenone were purchased from Sigma-Aldrich, USA. Acetonitrile, methanol, hexane, and phosphoric acid were purchased from Fisher Scientific, Fairlawn, NJ, USA. Water for HPLC was prepared by reverse osmosis and further purified by using synergy water purification system (Millipore, Bedford, MA, USA). Drug-free human plasma was obtained from the blood bank of King Faisal Specialist Hospital and Research Centre, Riyadh, Saudi Arabia, after approval of the institution's Research Ethics Committee.

\subsection{Chromatographic Conditions}

The mobile phase consisted of mobile phase-A: methanol, acetonitrile and water (15:35:50, v:v, pH 3.0, adjusted with phosphoric acid) and mobile phase-B: methanol, acetonitrile and water (90:5:5, v:v, pH 3.0, adjusted with phosphoric acid). Gradient elution started with mobile phase-A at a flow rate of 0.3 $\mathrm{ml} / \mathrm{min}$ for 7.0 minutes and switched immediately to mobile phase-B at flow rate of $0.3 \mathrm{ml} / \mathrm{min}$ for another 7.0 minutes.

\subsection{Standard and Control Solutions}

VD-2, VD-3, 25(OH)VD-2, 25(OH)VD-3, and IS stock solutions were prepared in methanol $(100 \mu \mathrm{g} / \mathrm{ml})$ and stored at $-20{ }^{\circ} \mathrm{C}$. Working solutions were prepared in human plasma (100 ng/ml). Nine calibration standards were prepared in human plasma in the range of 2.5-100 ng/ml. Dodecanophenone (IS) working solution was prepared in methanol $(250 \mathrm{ng} / \mathrm{ml})$. Four quality control samples were prepared: $2.5,7.5,50$, and $90 \mathrm{ng} / \mathrm{ml}$. The solutions were vortexed for one minute, and then $1.0 \mathrm{ml}$ aliquots were transferred into $7 \mathrm{ml}$ glass culture tubes and stored at $4{ }^{\circ} \mathrm{C}$ until used.

\subsection{Sample Preparation}

$100 \mu \mathrm{l}$ of the IS working solution was added to $1.0 \mathrm{of}$ plasma samples, calibration standards, and quality control samples in a $7 \mathrm{ml}$ culture tubes and vortexed. Acetonitrile $2.0 \mathrm{ml}$ was added to precipitate proteins. After vortexing, samples were extracted twice with 4.0 $\mathrm{ml}$ hexane and centrifuged at $6000 \mathrm{rpm}\left(8^{\circ} \mathrm{C}\right)$ for 10 min. and the clear supernatant layer was transferred to a clean culture tube and dried under gentle steam of nitrogen at room temperature. The residue was reconstituted in $100 \mu \mathrm{l}$ of mobile phase-A and $10 \mu \mathrm{l}$ of the clear solution was injected into the UPLC system.

\subsection{Calculation}

In order to correct for endogenous 25(OH)VD-3 level in "blank" plasma, we used the difference in peak area ratios between each consecutive concentration as the response (rather than the absolute peak area ratio). The difference in peak ratio was plotted against the concentration. For the other three analytes the peak area ratios was directly plotted against concentration, as there was no detectable VD-2, VD-3 or 25(OH)VD-2 levels in the blank plasma samples used. Accuracy (\%) was calculated as measured 
concentration divided by nominal concentration times 100 , whereas precision was expressed as coefficient of variation $(\mathrm{CV})$, calculated as standard deviation divided by mean concentration times 100 .

\section{Results and Discussion}

\subsection{Chromatographic Separation}

Fig. 1 depicts the chemical structures of the compounds used in the present study. Under the described conditions and gradient elution mode, VD-2, VD-3, 25(OH)VD-2, 25(OH)VD-3, and the internal standard peaks were well resolved. The retention times of 25(OH)VD-3, 25(OH)VD-2, IS, VD-2, and VD-3 were around 3.7, 4.1, 5.9, 12.1 and 12.4 minutes, respectively. Except for 25(OH)VD-3, no interfering peaks from endogenous plasma components were observed. Eight commonly used drugs (acetaminophen, caffeine, diclofenac sodium, omperazole, nicotinic acid, ascorbic acid, ibuprofen, and ranitidine) were screened for potential interference, none co-eluted with the components of interest. Typical chromatograms of methanol and human plasma spiked with VD-2, VD-3,
25(OH)VD-2, 25(OH)VD-3, and the IS are shown in Fig. 2.

\subsection{Method Validation}

The aim of the study was to develop a reliable and rapid method for simultaneous analysis of the two forms of vitamin D and their metabolites in human plasma. A minimal validation has been done according to US FDA guidelines for industrial bioanalytical method validation [16]. The calibration curves for the determination of VD-2, VD-3, 25(OH)VD-2, and 25(OH)VD-3 levels in human plasma were linear over the range 2.5-100 $\mathrm{ng} / \mathrm{ml}$ (Table 1). Precision and accuracy were determined in five replicates of four concentrations $(2.5,7.5,50$ and $90 \mathrm{ng} / \mathrm{ml})$. The results are presented in Table 2. The coefficients of variation for VD-2, VD-3, 25(OH)VD-2, and 25(OH)VD-3 were in the range of $1.9-13.4 \%$, and accuracy was in the range $82 \%-95 \%$. Recoveries of the four analytes at three different levels $(7.5,50$ and $90 \mathrm{ng} / \mathrm{ml})$ and the IS $(250 \mathrm{ng} / \mathrm{ml})$ were determined by comparing their peak areas in methanol samples and plasma samples.

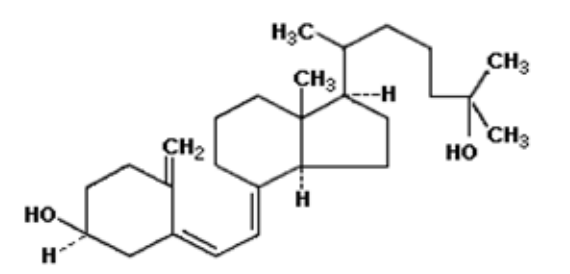

25-Hydroxy Vitamin D-3

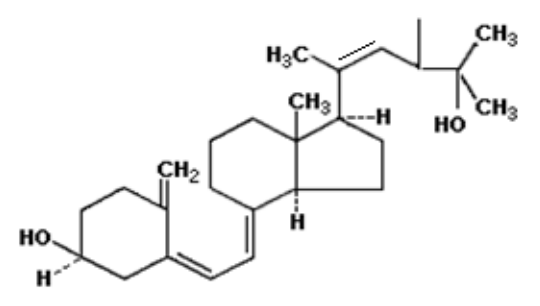

25-Hydroxy Vitamin D-2<smiles>CC(C)CCCC(C)[C@@H]1CC[C@H]2/C(=C/C=C3/C[C@@]([O])(O)CCC3(C)C)CCC[C@]12C</smiles>

Vitamin D-3<smiles>CCCCCCC(=O)c1ccccc1</smiles>

$\mathrm{N}$-Dodecanophenone

Vitamin D-2

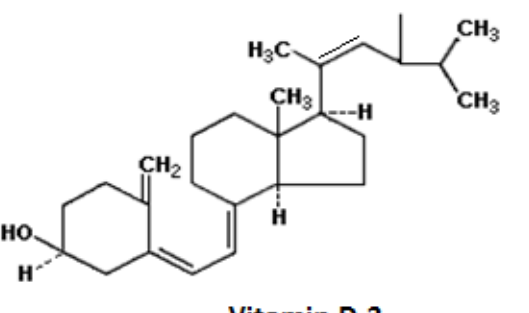


Rapid Determination of Vitamin D-2, D-3, and Their 25 Hydroxy Metabolites in

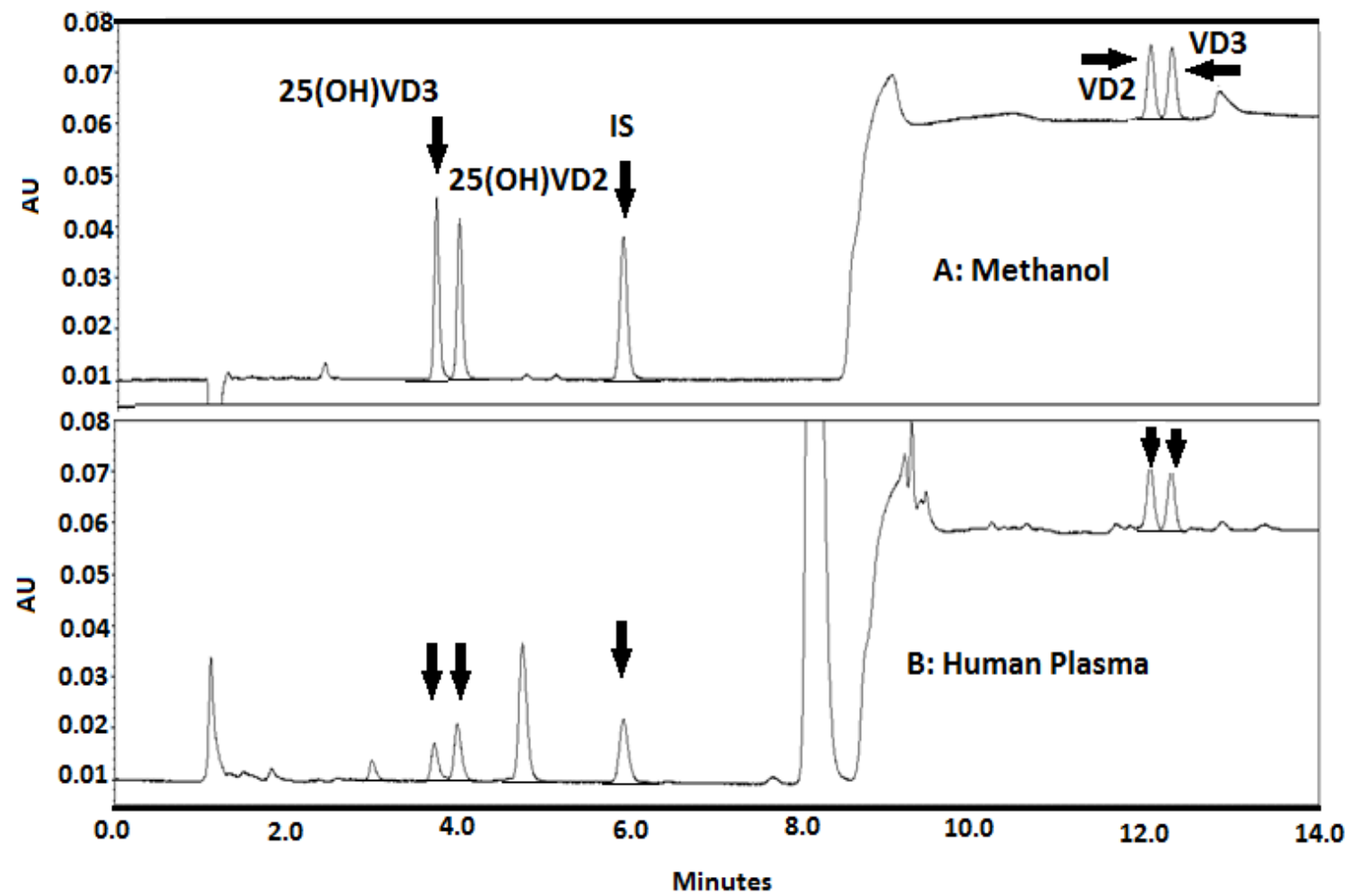

Fig. 2 Representative chromatograms of methanol (A) and human plasma (B) samples spiked with 25(OH)VD-2, 25(OH)VD-3, VD-2, VD-3, and dodecanophenone (IS).

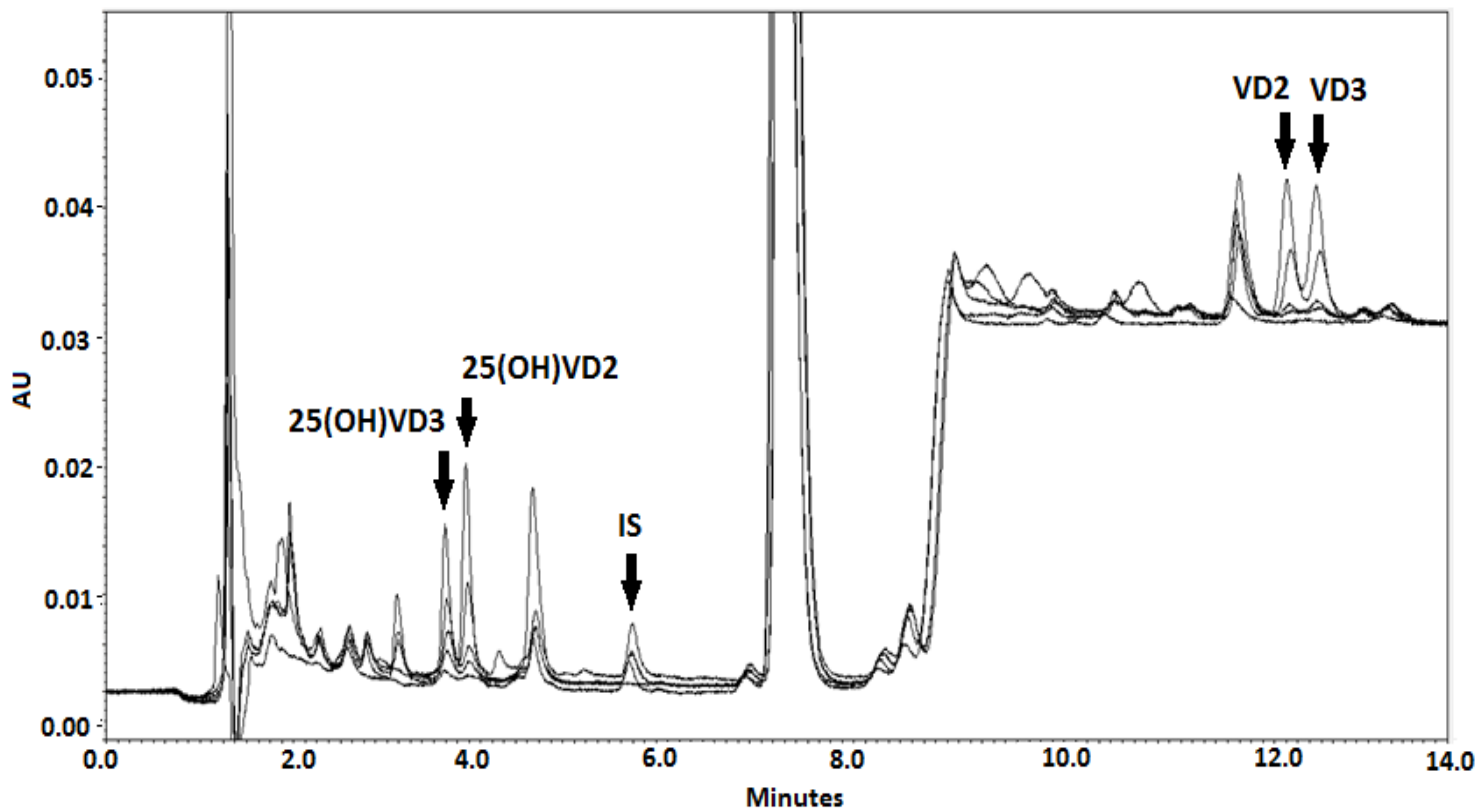

Fig. 3 Overlay chromatogram of extracts of $1.0 \mathrm{ml}$ human blank plasma, spiked with dodecanophenone (IS) and none or one of four concentrations of $(2.5,7.5,50$, and $90 \mathrm{ng} / \mathrm{ml})$ of $25(\mathrm{OH}) \mathrm{VD}-2,25(\mathrm{OH}) \mathrm{VD}-3$, VD-2, and VD-3. 
Table 1 Regression Analysis of six calibration curves.

\begin{tabular}{lllll}
\hline Parameter & $25(\mathrm{OH}) \mathrm{VD}-2$ & $25(\mathrm{OH}) \mathrm{VD}-3$ & VD-2 & VD-3 \\
\hline $\begin{array}{l}\text { Concentration range } \\
(\mathrm{ng} / \mathrm{ml})\end{array}$ & $2.5-100$ & $2.5-100$ & $2.5-100$ & $2.5-100$ \\
$\mathrm{R}^{2}(\mathrm{SD})$ & $0.9949(0.0022)$ & $0.9942(0.0037)$ & $\begin{array}{l}0.9928 \\
(0.0025)\end{array}$ & $\begin{array}{l}0.9962 \\
(0.0026)\end{array}$ \\
Slope (SD) & $0.0560(0.0017)$ & $0.0645(0.0021)$ & $\begin{array}{l}0.0193 \\
(0.0004)\end{array}$ & $\begin{array}{l}(0.0185 \\
(0.0008)\end{array}$ \\
Intercept (SD) & $0.3204(0.0854)$ & $0.1699(0.0392)$ & 0.1330 & 0.0504 \\
\end{tabular}

$\mathrm{R}^{2}$, Coefficient of determination; SD, Standard deviation.

Table 2 Intra- and inter-run precision and accuracy.

\begin{tabular}{|c|c|c|c|c|c|c|c|c|c|}
\hline \multirow{2}{*}{$\begin{array}{l}\text { Component } \\
\text { Concentration } \\
(\mathrm{ng} / \mathrm{ml})\end{array}$} & \multirow{2}{*}{$\begin{array}{l}\text { Measured } \\
\text { Parameters }\end{array}$} & \multicolumn{4}{|c|}{ Intra-day $(n=10)$} & \multicolumn{4}{|c|}{ Inter-day $(n=20)$} \\
\hline & & 2.5 & 7.5 & 50 & 90 & 2.5 & 7.5 & 50 & 90 \\
\hline \multirow{4}{*}{$25(\mathrm{OH}) \mathrm{VD}-3$} & Mean (ng/ml) & 2.1 & 7.1 & 47.6 & 85.5 & 2.2 & 7.0 & 45.8 & 85.5 \\
\hline & $\mathrm{SD}(\mathrm{ng} / \mathrm{ml})$ & 0.1 & 0.2 & 0.9 & 1.7 & 0.2 & 0.3 & 1.5 & 2.4 \\
\hline & $\mathrm{CV}(\%)$ & 5.1 & 3.0 & 1.9 & 2.0 & 6.8 & 4.4 & 3.4 & 2.8 \\
\hline & Accuracy $(\%)$ & 85 & 94 & 95 & 95 & 88 & 93 & 92 & 95 \\
\hline \multirow{4}{*}{$25(\mathrm{OH}) \mathrm{VD}-2$} & Mean (ng/ml) & 2.2 & 7.0 & 47.6 & 85.0 & 2.2 & 7.0 & 47.2 & 85.1 \\
\hline & $\mathrm{SD}(\mathrm{ng} / \mathrm{ml})$ & 0.1 & 0.3 & 0.9 & 1.4 & 0.2 & 0.2 & 1.1 & 2.4 \\
\hline & $\mathrm{CV}(\%)$ & 5.8 & 4.1 & 1.9 & 1.7 & 6.8 & 3.4 & 2.3 & 2.8 \\
\hline & Accuracy $(\%)$ & 86 & 93 & 95 & 94 & 88 & 93 & 94 & 95 \\
\hline \multirow{4}{*}{ VD-2 } & Mean (ng/ml) & 2.1 & 7.0 & 47.6 & 84.2 & 2.2 & 7.0 & 47.2 & 84.2 \\
\hline & $\mathrm{SD}(\mathrm{ng} / \mathrm{ml})$ & 0.3 & 0.3 & 0.9 & 2.5 & 0.2 & 0.3 & 1.1 & 2.4 \\
\hline & $\mathrm{CV}(\%)$ & 13.4 & 4.8 & 1.9 & 2.9 & 10.9 & 4.0 & 2.3 & 2.9 \\
\hline & Accuracy $(\%)$ & 82 & 93 & 95 & 94 & 87 & 93 & 94 & 94 \\
\hline \multirow{4}{*}{ VD-3 } & Mean (ng/ml) & 2.1 & 6.3 & 46.1 & 84.7 & 2.1 & 6.3 & 45.6 & 83.6 \\
\hline & $\mathrm{SD}(\mathrm{ng} / \mathrm{ml})$ & 0.2 & 0.3 & 2.1 & 2.5 & 0.2 & 0.5 & 1.9 & 2.6 \\
\hline & CV $(\%)$ & 9.8 & 5.5 & 4.5 & 3.0 & 8.4 & 7.6 & 4.1 & 3.1 \\
\hline & Accuracy (\%) & 85 & 83 & 92 & 94 & 84 & 84 & 91 & 93 \\
\hline
\end{tabular}

$\overline{\mathrm{SD}}$, standard deviation. $\mathrm{CV}$, coefficient of variation as a measurement of imprecision (standard deviation divided by mean measured concentration) $\times 100$. Accuracy, measured level divided by nominal level $\times 100$.

Recovery of VD-2, VD-3, 25(OH)VD-2, and $25(\mathrm{OH}) \mathrm{VD}-3$ was in the range $77 \%-93 \%$. It was $85 \%$ for the IS. Limits of detection were $0.8 \mathrm{ng} / \mathrm{ml}$ for 25(OH)VD-3 and 25(OH)VD-2 and $1.5 \mathrm{ng} / \mathrm{ml}$ for VD-2 and VD-3. Fig. 3 depicts overlay chromatogram of blank and the four quality control samples.

\section{Conclusions}

The described UPLC method is simple and rapid, and allows simultaneous measurement of VD-2, VD-3, $25(\mathrm{OH}) \mathrm{VD}-2$, and $25(\mathrm{OH}) \mathrm{VD}-3$ levels in human plasma.

\section{Acknowledgements}

This work funded by a grant to Dr. Muhammad M Hammami, from the King Abdul-Aziz City for Science and Technology, under National Comprehensive Plan for Science and Technology, Riyadh, Saudi Arabia, (Biotech:10-MED 1362-20).

\section{Reference}

[1] Holick, M. F. 2007. "Vitamin D Deficiency." N. Engl. J. Med. 357 (3): 266-81.

[2] Kulie, T., Groff, A., Redmer, J., Hounshell, J., and Schrager, S. 2009. "Evidence-Based Review." The J. Am. Board of Fam. Med. 22 (6): 698-706. 
[3] DeLuca, H. F., and Schnoes, H. K. 1983. "Vitamin D: Recent advances." Annu. Rev. Biochem. 52 (1): 411-39.

[4] Hollis, B. W. 2007. "Circulating Vitamin D-3 and 25-Hydroxyvitamin D in Humans: An Important Tool to Define Adequate Nutritional Vitamin D Status." J. Steroid Biochem. Mol. Biol. 103 (3-5): 631-4.

[5] Holick, M. F., and Tai Chen, C. 2008. "Vitamin D Deficiency: A Worldwide Problem with Health Consequences.” Am. J. Clin. Nutr. 87 (4): 1080S-6S.

[6] Hollis, B. W., Kamerud, J. Q., Selvaag, S. R., and Lorenz, J. D. 1993. "Determination of Vitamin D Status by Radioimmunoassay with a ${ }^{125}$ I-Labeled Tracer." Clin. Chem. 39 (3): 529-33.

[7] Eisman, J. A., Shepard, R. M., and DeLuca, H. F. 1997. "Determination of 25-Hydroxyvitamin D2 and 25-Hydroxyvitamin D3 in Human Plasma Using High-Pressure Liquid Chromatography." Anal. Biochem. 80 (1): 298-305.

[8] Shimada, K., Mitamura, K., Kitama, N., and Kawasaki, M. 1997. "Determination of 25-Hydroxyvitamin D3 in Human Plasma by Reversed-Phase High Performance Liquid Chromatography with Ultraviolet Detection." J. Chromatogr B. Biomed. Sci. Appl. 689 (2): 409-14.

[9] Amy, K. S., Thomas, J. L., Deborah, E. B., and Sayed, M. H. S. 2006. "Quantification of Serum 25-Hydroxyvitamin $\mathrm{D}_{2}$ and $\mathrm{D}_{3}$ Using HPLC-Tandem Mass Spectrometry and Examination of Reference Intervals for Diagnosis of Vitamin D Deficiency." Clin. Pathol. 125 (6): 914-20.

[10] Takeuchi, A., Ishida, Y., Sonoko, M., Okano, T., Nishiyama, S., Matsuda, I., and Kobayashi, T. 1997. "Simplified Method for the Determination of 25-hydro and 1 $\alpha, 25$-Dihydroxy Metabolites of Vitamin D2 and D3 in Human Plasma Application to Nutritional Studies." J. Chromatogr. B: Biomedical Sciences and Appl. 691 (2): 313-9.
[11] Tsugawa, N., Suhara, Y., Kamao, M., and Okano, T. 2005. "Determination of 25-Hydroxyvitamin D in Human Plasma Using High-Performance Liquid Chromatography-Tandem Mass Spectrometry." Anal. Chem. 77 (9): 3001-7.

[12] Manunsell, Z., Wright, D. J., and Rainbow, S. J. 2005. "Routine Isotope-dilution Liquid Chromatography-tandem Mass Spectrometry Assay for Simultaneous Measurement of the 25-Hydroxy Metabolites of Vitamin D2 and D3." Clin. Chem. 51 (9): 1683-90.

[13] Saenger, A. K., Laha, T. J., Bremner, D. E., and Sadrzadeh, S. M. 2006. "Quantification of Serum 25-Hydroxyvitamin D2 and D3 Using HPLC-Tandem Mass Spectrometery and Examination of Reference Intervals for the Diagnosis of Vitamin D Deficiency." Am. J. Clin. Pathol. 125 (6): 914-20.

[14] Susan, K., John, H., Lisa, C., and Minchael, W. A. 2009. "A Simple Automated Solid-Phase Extraction Procedure for Measurement of 25-Hydroxyvitamin D3 and D2 by Liquid Chromatography-Tandem Mass Spectrometry." Ann. Clin. Biochem. 46 (3): 226-30.

[15] Aksnes, L. 1992. “A Simplified High-Performance Liquid Chromatographic Method for Determination of Vitamin D3, 25-Hydroxyvitamin D2, and 25-Hydroxyvitamin D3 in Human Serum." Scandinavian Journal of Clinical and Lab. Investigation 52 (3): 177-82.

[16] Alvi, S. N., Yusuf, A., and Hammami, M. M. 2012. "Simultaneous Quantification of Vitamin D-2, Vitamin D-3, and Their 25-Hydroxy Metabolites in Human Plasma by High Performance Liquid Chromatography." $J$. Bioequiv. Availab. S14 (007): 1-5.

[17] Guidance for Industry. 2001. "Bioanalytical Method Validation." US Department of Health Services, Food and Drug Administration, CDER, CVM. 